\title{
THE METEOROLOGICAL VARIABILITY OF THE YEAR 2019 AND ITS REFLEX ON THE SUCEAVA MUNICIPALITY POPULATION HEALTH CONDITION
}

DOI: http://dx.doi.org/10.18509/GBP.2020.22

UDC: 551.584.5:614.1(498)

\author{
Dumitru Mihăilă ${ }^{1}$ \\ Sînziana Silișteanu² \\ Mihaela Ţiculeanu - Ciurlică ${ }^{1}$ \\ Petrut Ionel-Bistricean ${ }^{3 \& 1}$ \\ ${ }^{1}$ Department of Geography, Faculty of History and Geography, Stefan cel Mare University, \\ Suceava, Romania \\ ${ }^{2}$ Department of Health and Human Development, Faculty of Physical Education and Sports, \\ Stefan cel Mare University, Suceava, Romania \\ ${ }^{3}$ Regional Meteorological Centre of Moldova, National Meteorological Administration, \\ Suceava, Romania
}

\begin{abstract}
The study aims to assess, both directly and indirectly, the impact of day-to-day variability in meteorological elements that define weather on health/morbidity conditions of the Suceava municipality population for the year 2019. Population morbidity is generated by a complex interplay of factors which include the meteorological factors. A person's request for medical services does not necessarily represent a reflection of the weather conditions. Yet, meteorological factors enhance or trigger certain diseases, under specific temporal and spatial circumstances. The present study uses a complex database of meteorological and clinical observations to identify clear, redundant temporal patterns in health conditions of urban population (Suceava Municipality), in relation to meteorological variables and other elements of the geographic setting.
\end{abstract}

Keywords: Suceava, morbidity, population health, weather conditions

\section{INTRODUCTION}

In densely populated areas, high, short-term variability in meteorological parameters can trigger numerous health problems related to adaptation, discomfort and even pathology in large categories of population (e.g., elderly, children) that are more sensitive to greaterthan-usual magnitudes of variation in weather conditions.

Any meteorological factor or element may induce discomfort / stress or certain pathologies through its variability and extreme values. Of these, air temperature is one of the meteorological elements with clear biotropic effects. Direct exposure to negative temperature can generate chills, frostbite and hypothermia, whilst indirect exposure may result in a wide range of conditions ("a frigore" diseases) such as: respiratory tract diseases/illnesses (common cold, rhinitis, pharyngitis, laryngitis, bronchitis, bronchopneumopathy), cardiovascular (obliterating endarteritis, ischemic heart disease, peripheral vascular disease, hypertension and even heart attack), locomotor (polyarthritis, arthrosis, lombosciatica) and a series of dermatoses [1], [2]. Moreover, low temperature favors the occurrence of renal (chronic nephritis) and neurological (neuralgia, facial paralysis) disorders [2]. Population categories that are the most affected by low 
temperature are children, the elderly, patients with diabetes, asthmatics, patients with hepatic or renal disease, with leukemia, anemia and so on. Sudden variations in temperature are more difficult to bear by the aforementioned population categories (but also by healthy people), and the association between low temperature, high humidity, snow accumulation, ice and strong wind can trigger or enhance respiratory, neuromotor and traumatic conditions. [1]. In Suceava municipality area, the most critical health problems caused by negative temperature are triggered by the advection of polar and arctic air masses, particularly if these advections occur outside the cold season. Very high temperature and high positive temperature variations (generally caused by tropical heat waves) can generate heat syncopes, hydroelectrolytic disorders and hyperthermia associated with a series of conditions of the cardiovascular system (blood pressure disorders, coronary arteriosclerosis), renal system (decreased diuresis), hypofunctions of the gastric secretory glands and the recrudescence of chronic dermatoses [1]. There are studies showing that during heat waves mortality is higher than during cold waves [3], due to the typology of heat waves and association with other climatic risk phenomena, with profound social-economic consequences (drought, famine, military conflicts). A recent study sheds a more complete perspective on these phenomena [4]. Different thresholds and connections were identified between air humidity, expressed by the surface tension of water vapors and the state of comfort / discomfort of the human body [5], whereby such connections were found for the entire Romania [6] as well as regionally, i.e., for the Suceava Plateau area [7a], [7b]. The relevant literature uses the phrase "psychological moisture" [8], as it is known that the intervals with high humidity are more difficult to bear by humans than those with low humidity. High humidity associated with high or low temperature create greater adaptation problems for the body. A drier air, against the background of high or low temperature, is preferable to the previous situation [9]. The dry and cold air favors the occurrence of respiratory tract diseases and the allergic dermatitis in the cold season [1], [3], deepening the negative mental states in affected population categories [10]. Wet and cold air favors an increase in the sensation of cold, as well as respiratory, infectious-contagious, rheumatic and nervous system diseases [1]. Wet and warm air triggers migraines [3] and a series of dermatoses. High humidity, either characteristic of hot or cold air, associated with active air dynamics indirectly favors the survival, development and spread of pathogens, of carriers of parasites and microbes [11] or "microbial aerosols" [8]. Dry air favors the accumulation of pollutants in the urban air, with the occurrence of dry urban fog, thus indirectly lowering air quality. Large variations and extreme values in atmospheric pressure have a rapid effect on humans. When the pressure drops, people with illnesses such as chronic sinusitis and nasal congestion are the most affected. Low pressure favors respiratory tract diseases, asthmatic symptoms, increased number of renal colic, pulse frequency disorders, heart rate destabilization, heart attack and hypertonic disease [1]. High pressure enhances pain in patients with ulcer, increases blood pressure, whilst a rapid increase in pressure rises the incidence of cerebral hemorrhage and the frequency of cor pulmonale [9]. Wind exerts pressure on the body and, depending on its intensity, stimulates skin nerves to varying degrees, causes angina attacks, thus negatively affecting the respiratory and nervous system [12]. Hot, dry wind causes irritability, fatigue, headaches, nervous disorders, hemorrhages, venous stasis, water retention, scarring pain, whereas cold and wet wind may enhance symptoms of asthma, laryngeal croup, skin allergies, fatigue, decreased work capacity, insomnia, anxiety, depression, angina attack, extrasystoles, heart attack [9], [13], [14], [15], [10]. Furthermore, other meteorological 
elements (cloudiness, sunshine duration and global radiation) or related to air quality (such as carbon monoxide - $\mathrm{CO}$, tropospheric ozone - $\mathrm{O}_{3}$, nitrogen dioxide - $\mathrm{NO}_{2}$, sulfur dioxide - $\mathrm{SO}_{2}$ and particulate matter - $\mathrm{PM}_{10}$ ) play an important role in the overall health conditions or morbidity of the Suceava municipality population.
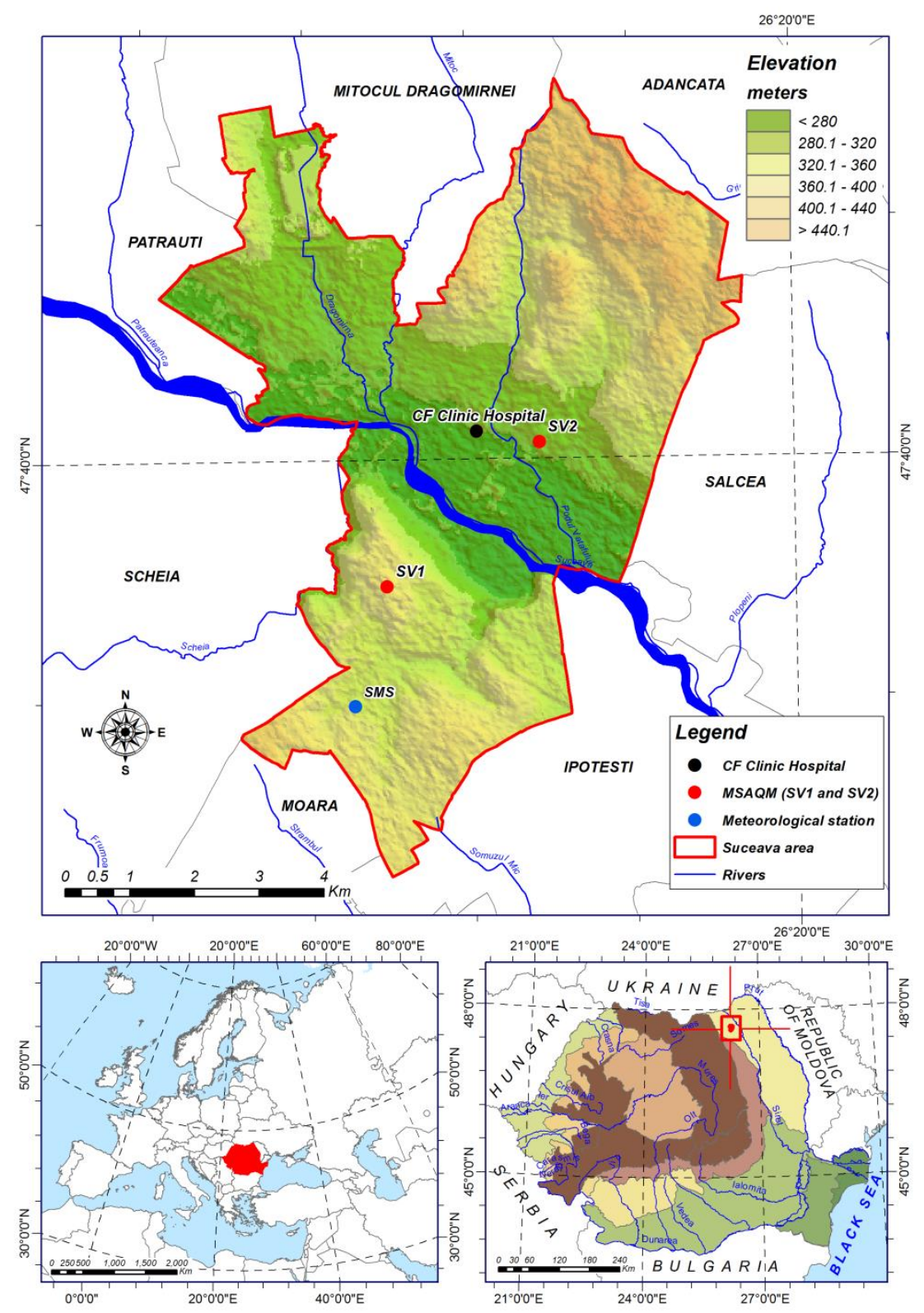

Figure 1 Geographic and mathematical location of meteorological and medical observation points in Suceava urban area - top, Romania - bottom right and Europe - bottom left

The main aim of the study is to evaluate the variability of eight large groups of medical conditions (inferred from the number of patients who requested specialized medical assistance in two medical structures in the Suceava municipality) in relation to the variability in key weather elements (air temperature, air humidity, vapor pressure, air pressure, wind speed, cloudiness and precipitation) over the year 2019. We therefore aimed to find any likely direct or indirect links between meteorological factors and the overall population morbidity, by identifying critical periods characterized by peaks in 
requested medical assistance and testing for seasonality in medical conditions that could be connected with meteorological seasonality.

\section{MATERIALS AND METHODS}

\section{Study area}

The population of the Suceava urban agglomeration (NE Romania - Fig. 1) on census day 2011 was 116404 inhabitants. Their life quality depends directly on the physical and chemical characteristics of the urban air, which also impact daily social-economic activities. Suceava is an important commercial and tourism center. Its climate is temperate-continental with moderate features, however, weather conditions during the year are highly variable. Even though tropical weather occurs episodically, especially in summer (1.5\% of an average year), the high temperature ranges are characteristic of the local climate and cannot be ignored. Cold, frosty weather is specific to winter and the cold season, and reaches $8 \%$ of time during an average year. Therefore, from a bioclimatic point of view, Suceava climate shows features that are more turn-applicant than sedative [16].

\section{Research Methodology}

Our research was based on the hypothesis that unstable weather intervals result in higher morbidity. We therefore comparatively analyzed any likely weather-pathology links, over various timespans, using daily to seasonal data. At the season and month level, the influence of anthropogenic biases (see below) on the correlation between the number of medical consultations and the weather patterns is less clear. On the other hand, for daily data, the weather- medical consultations relationships appear more shaped by anthropogenic biases such as: working hours of the medical cabinets, i.e., Monday to Friday, bank or religious holidays and other non-working days when no consultations are made and when patients can only use the emergency medical system, temporal or financial constraints which can lead to delays in asking for medical consultations etc.

\section{Data and metods}

Our study is based on daily weather data from the Suceava Meteorological Station and on weather and air quality data from the SV1 and SV2 air quality monitoring stations, all located in Suceava urban area. In the test medical offices 8750 patients of different ages were seen in 2019 (Fig. 2) by two general practitioners during 251 days of consultations, thus returning an average number of 17.43 consultations per physician / day.

As the working week has only five days, most patients were seen on Mondays and Tuesdays, on Wednesdays and Thursdays their number followed a decreasing trend, and on Friday it rose again (Fig. 3). Although morbidity is controlled by many socio-economic and biological factors and not by the doctors' working hours (Monday to Friday), the daily and weekly trends in this demographic indicator are strongly shaped by this aspect.

The higher incidence of cardiovascular diseases caused a maximum in the number of patients with such diseases in 2019 (Fig. 4). This first category of disorders was followed by that of patients who asked for medical assistance for locomotor, respiratory, digestive, renal, neurological, psychiatric and metabolic-endocrine conditions (Fig. 4). 


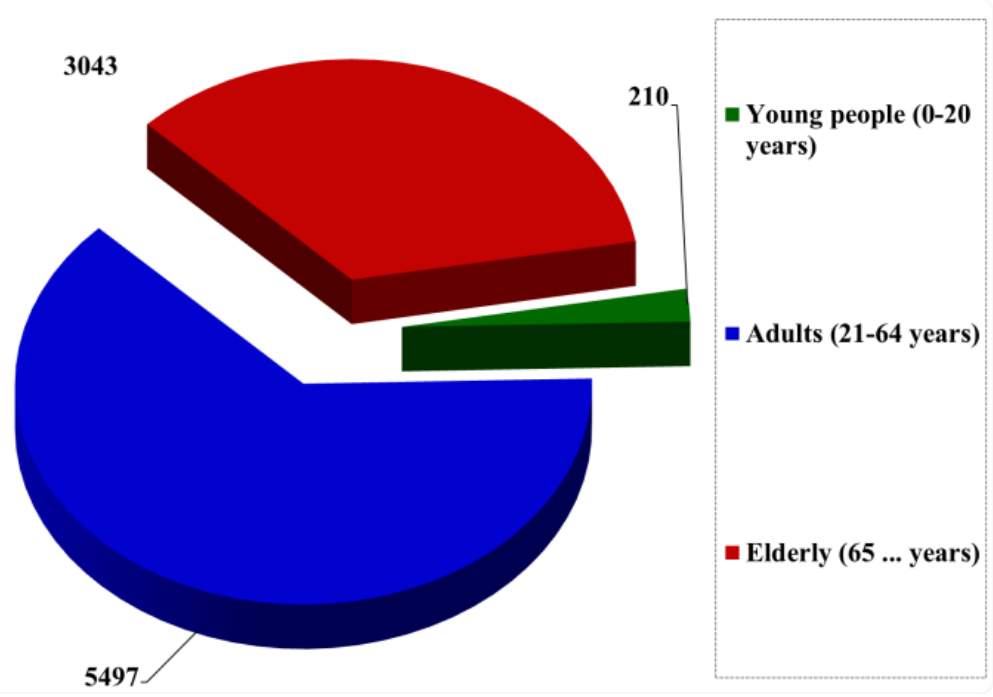

Figure 2. Distribution by age group of the number of patients seen in the two test doctor's offices in Suceava in 2019 (CMT_SV_2019)

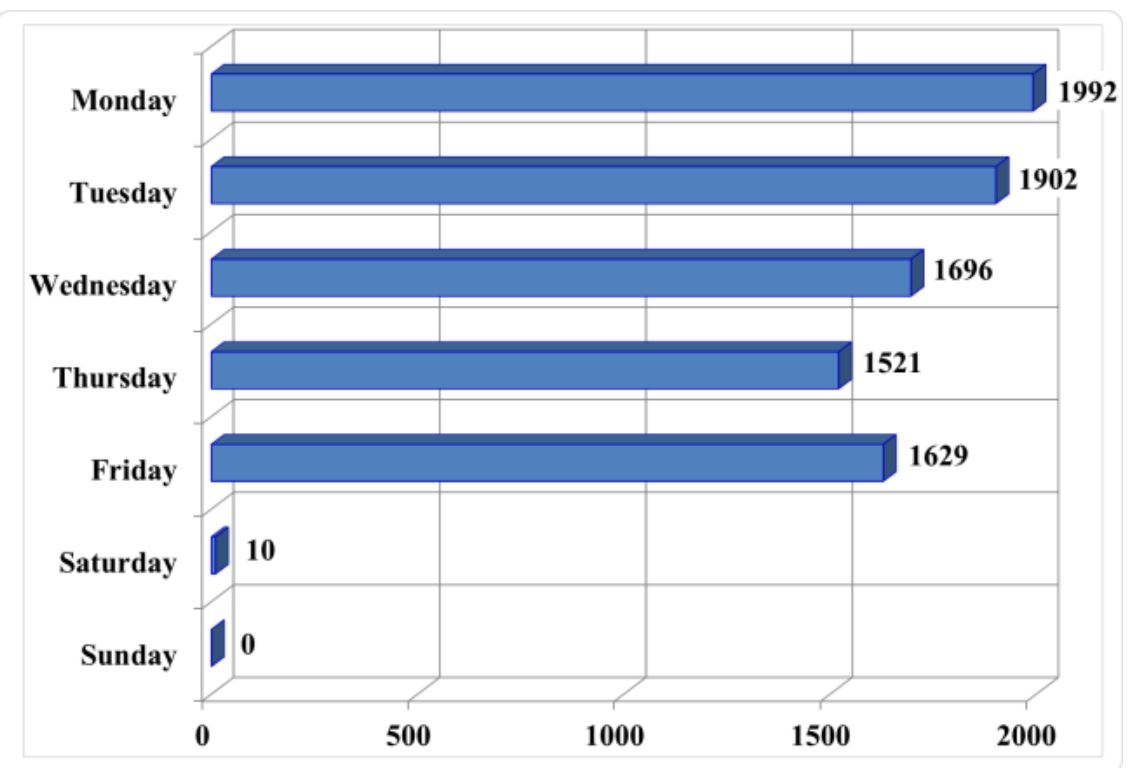

Figure 3. Distribution by week days of the number of patients seen in the two CMT_SV_2019

\section{RESULTS AND DISCUSSIONS}

From the meteorological point of view, 2019 was a hot year in Suceava, as average monthly temperature exceeded the climatological averages in nine months, was equal to climatological averages in two months and was below the climatological average only in January. 2019 was dry, with rainfall deficit in nine of the 12 months of the year. Only May and June were characterized by rainfall surplus, but its effects were canceled by the six dry months which followed in the second part of the year.

From the point of view of air quality, for SO2 concentration in 2019 neither the hourly limit values $(350 \mu \mathrm{g} / \mathrm{m} 3)$ nor the daily limits $(125 \mu \mathrm{g} / \mathrm{m} 3 /$ day $)$ were exceeded at both SV1 and SV2 measuring locations. For NO2, the hourly limit value of $200 \mu \mathrm{g} / \mathrm{m} 3$ was exceeded at station SV2 only in two cases. For O3, the alert threshold ( $240 \mu \mathrm{g} / \mathrm{m} 3$ - 1 hour average) was not exceeded in any situation (the hourly maximum was $129.69 \mu \mathrm{g} / \mathrm{m} 3$ in SV1 and $151.84 \mu \mathrm{g} / \mathrm{m} 3$ in SV2. For CO, there were 
no cases when concentrations exceeded the limit value, set for the protection of human health, i.e., the maximum daily value of the 8 -hour averages is $10 \mathrm{mg} / \mathrm{m} 3$. The maximum value for this indicator was $4.65 \mathrm{mg} / \mathrm{m} 3$ at SV2. For PM10 concentrations, i.e. particulate matter $\leq 10 \mu \mathrm{m}$, the daily limit value of $50 \mu \mathrm{g} / \mathrm{m} 3$, above which human health is threatened, was exceeded in 2019 at SV1 over eight days and at SV2 over 36 days. Local environment in the areas where the two doctor's offices are located (Fig. 1) is characterized by the highest variability in weather elements (compared to SV1 and SMS) and lower air quality (compared to SV1).

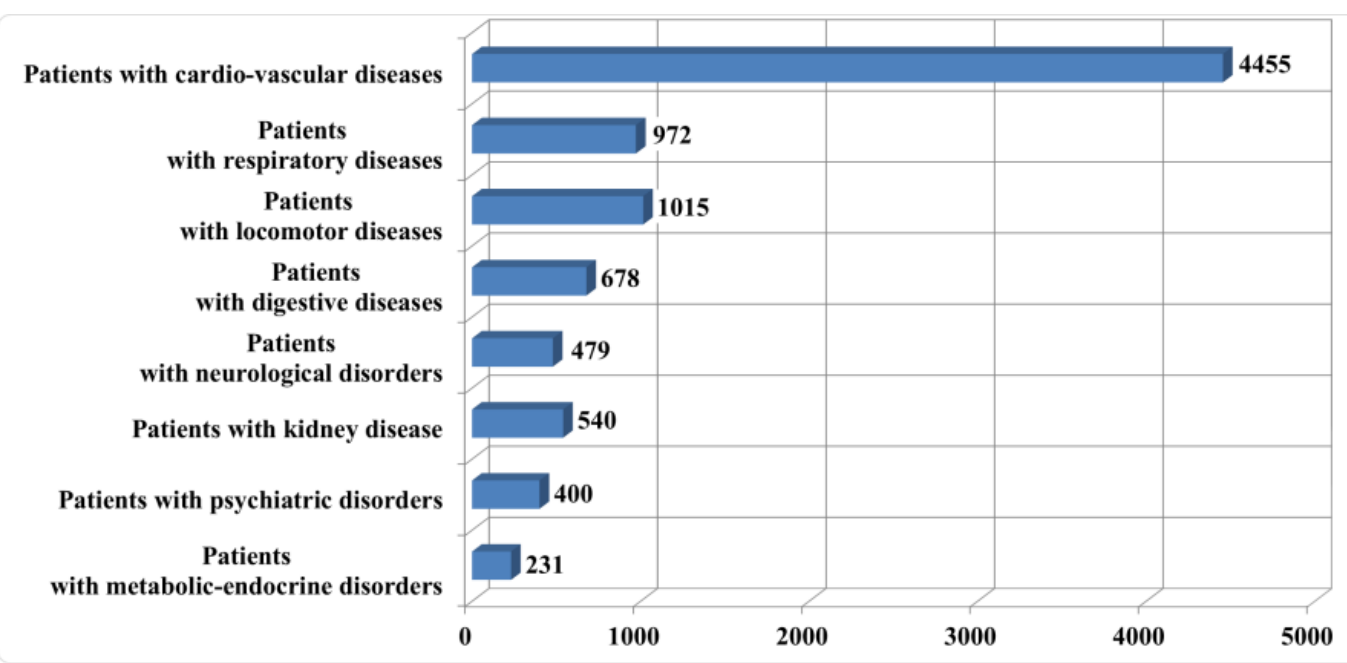

Figure 4 Distribution of the total number of patients according to their medical condition in the two CMT_SV_2019

The number of patients seen in the cold season of the year was around 400 people belonging to all age groups, higher than in the warm season (Fig. 5), and also higher in the autumn and winter compared to spring and summer (Fig. 6).

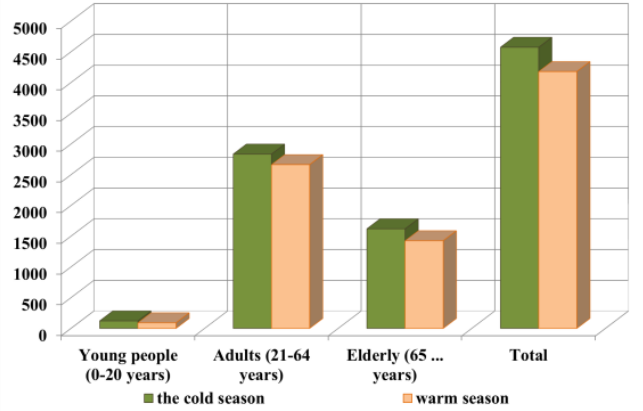

Figure 5. Distribution of the number of patients by age groups seen in the two CMT_SV_2019 during the cold and hot season

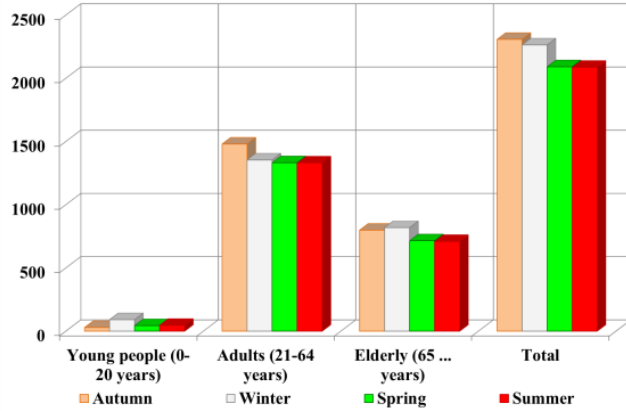

Figure 6. Distribution of the number of patients by age groups seen in the two CMT_SV_2019 during the autumn, winter, spring and summer

Based on Fig. 7 it can be inferred that in the cold season months morbidity was slightly higher than in the warm season months. Patients with cardiovascular disease were the most numerous. The highest number of patients with such conditions were seen by doctors in the autumn, winter and spring, and their number decreased by more than half in the summer months - Fig. 8. Among the most frequent consultations for cardiovascular problems were hypertension (favored by high temperature, by marked increases or decreases in air temperature and pressure), ischemic heart disease (favored by low 
temperature) and heart rhythm disorders (favored by both high and low temperature, but also by pressure variability).

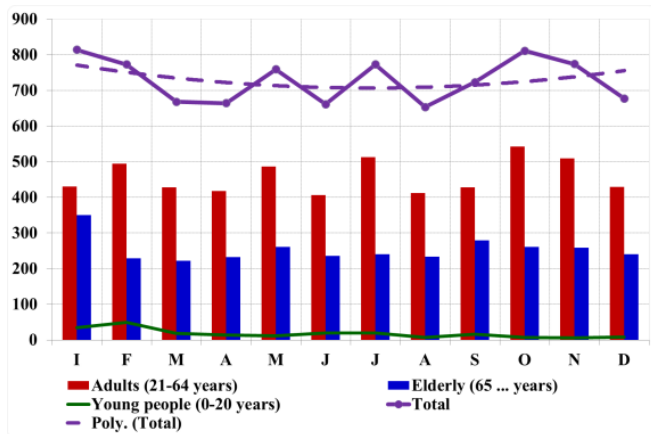

Figure 7. Monthly variability of the number of patients by age-groups seen in the two CMT_SV_2019

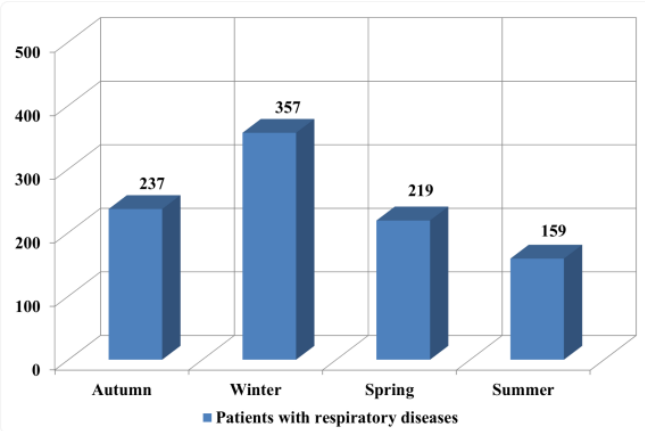

Figure 9. Seasonal variability of the number of patients with respiratory disease seen in the two CMT_SV_2019

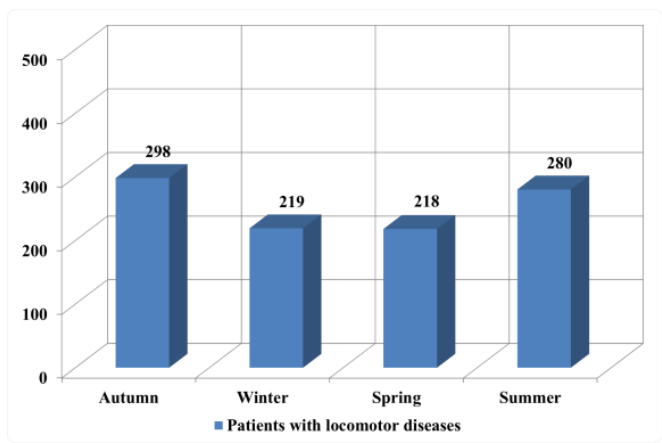

Figure 11. Seasonal variability of the number of patients with locomotor disorders seen in the two CMT_SV_2019

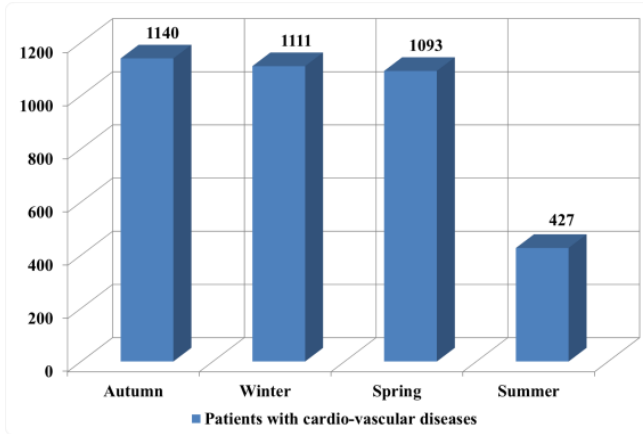

Figure 8. Seasonal variability of the number of patients with cardiovascular disease seen in the two CMT_SV_2019

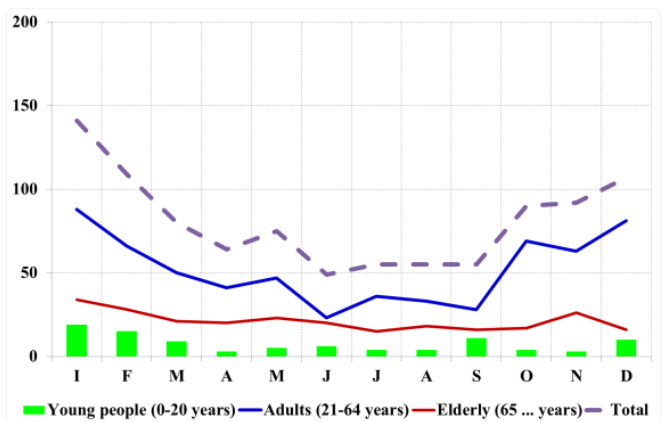

Figure 10. Monthly variability of the number of patients with respiratory problems by age groups seen in the two CMT_SV_2019

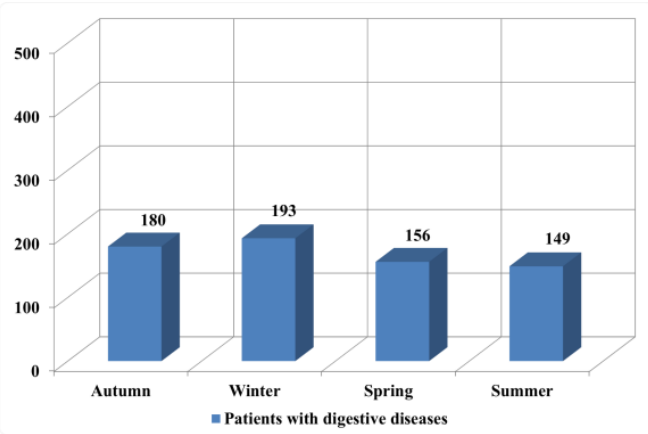

Figure 12. Seasonal variability of the number of patients with digestive disorders seen in the two CMT_SV_2019

Most cases of disease in patients with respiratory disorders occur during the winter months (Figs. 9, 10), while the fewest cases are recorded during summer. Occurrence of common cold is favored by low temperature and strong wind. Sinusitis, pharyngitis and laryngitis are also favored by low temperature, marked temperature decrease and highintensity wind. Bronchitis and pneumonia are also influenced by low temperature and strong wind. 
Patients with locomotor disfunctions exhibit the most impairments in winter and spring, however, the majority of them see a physician during summer and autumn, to ask for a medical note for cure in dedicated balneoclimatic resorts (Fig. 11). All locomotor disfunctions are favored by low temperature, high temperature variability, cloud cover and precipitation. Elevated air humidity and marked increase in pressure favor osteoarthritis affecting various parts of the body, rheumatoid polyarthritis, ankylosing spondylitis, cervicobrachial neuralgia. Strong wind favors osteoarthritis in various parts of the body, rheumatoid arthritis, ankylosing spondylitis, scapulohumeral periarthritis, lumbar discopathy and synovitis.

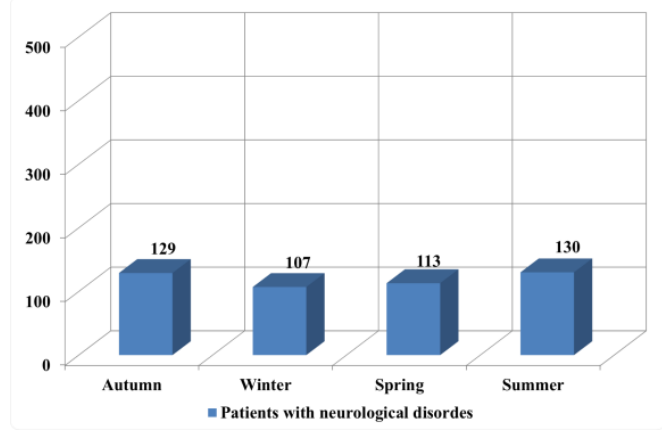

Figure 13. Seasonal variability of the number of patients with neurological disorders seen in the two CMT_SV_2019

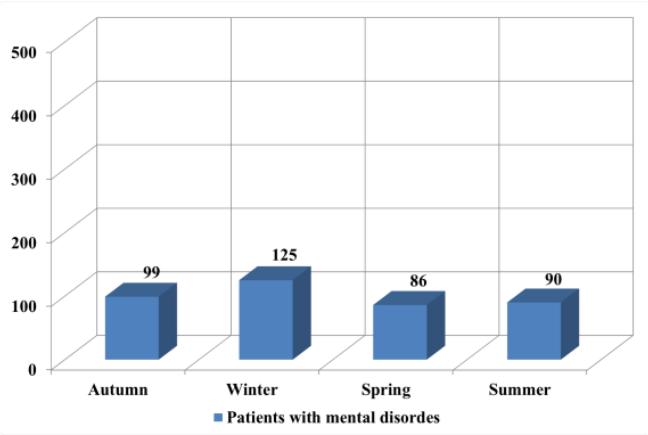

Figure 15. Seasonal variability of the number of patients with mental disorders seen in the two CMT_SV_2019

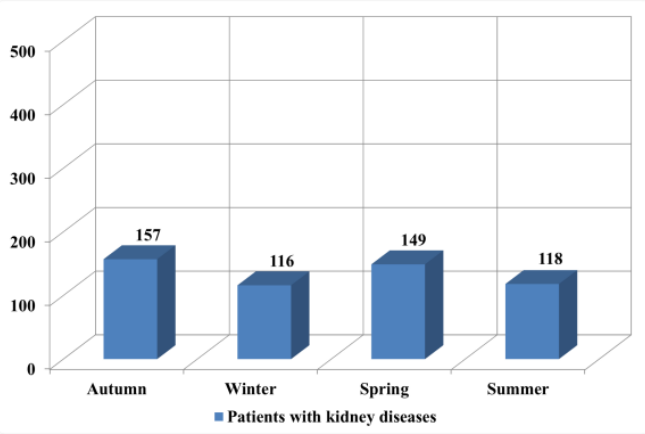

Figure 14. Seasonal variability of the number of patients with renal disorders seen in the two CMT_SV_2019

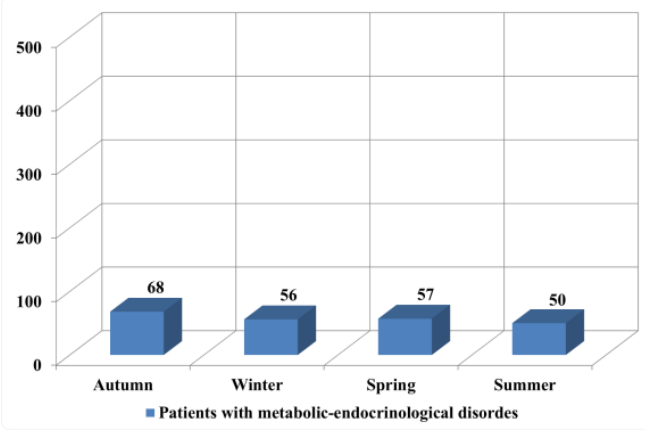

Figure 16. Seasonal variability of the number of patients with metabolic-endocrinological disorders seen in the two CMT_SV_2019

With regard to digestive diseases, long-term medical practice revealed that infectious digestive disorders (enteritis, gastroduodenitis) increase in summer and furthermore, due to the lower amount of body fluids and vasodilation, the number of biliary and pancreatic colic also increases. In spring and autumn, chronic conditions (gastritis, ulcers) may become acute. In Suceava, in 2019, the highest number of patients with digestive disorders (gastritis, ulcer, cholecystitis, pancreatitis) who requested medical consultations was recorded in autumn and winter (Fig. 12). We suggest that this situation was triggered by the abnormally hot and dry June-December interval (average temperature for the 6 months was $2.6^{\circ} \mathrm{C}$ above the climatological average, and precipitation amount was 203 $\mathrm{mm}$ lower than the average precipitation typical for this interval of the year) which affected the seasonal pattern of reported digestive conditions.

Most patients with neurological disorders (stroke, vertebrate-basilar insufficiency, facial paresis, vertigo syndrome, epilepsy seizures) (Fig. 13) requested specialized medical 
consultations in autumn and winter. Strokes are favored by high temperature and large variations in atmospheric pressure. Vasoconstriction at low temperature may cause spasm and ischemic stroke. As temperature rises, vasodilation may lead to an increase in blood pressure and may therefore cause hemorrhagic stroke. Vertebrate-basilar insufficiency, facial paresis and vertigo syndrome are favored by low temperature, strong wind and high temperature variations. Epilepsy seizures are favored by high temperature and more often by temperature increase.

Patients with kidney disease (urinary tract infections, kidney colic, cystitis, urethritis) (Fig. 14) requested more consultations during the transition seasons - spring and autumn. Cystitis and urethritis are conditions aggravated by marked temperature increases and high air humidity. Kidney seizures may also occur during summer (or during very hot episodes) due to the decrease in the amount of body water through perspiration. The number of cases with kidney colic increases both in summer, due to the decrease in the amount of body fluids and vasodilation, and during cold episodes, as a result of vasoconstriction.

Most patients with mental disorders (depression, anxiety, behavioral disorders) (Fig. 15) requested medical support in autumn and especially winter. Low temperature and enhanced pressure variability (at both high and low pressure) are favoring factors for these conditions. The transition between the autumn and winter seasons (November to February), when high humidity generates fog and persistent stratiform clouds, when day length decreases and cloudy skies with no sun occur over days and weeks, favors the development of these conditions. On the other hand, very hot intervals may also aggravate a number of mental illnesses.

For patients with metabolic-endocrinological disorders (gout-pus, exacerbation of endocrine disorders, diabetes crises- hyper- or hypoglycemia) (Fig. 16) we did not identify relevant seasonal differences, however, in the cold season and intervals of the year, the number of such diseases is slightly higher than in the hot season or warmer intervals.

By further analyzing the groups of days and isolated days in which the number of medical conditions was higher, we observed several situations when meteorological factors likely played a more important role in the matrix of the factors controlling morbidity.

Between 12.01 and 18.01, air temperature increased above the freezing threshold and the average day-night temperature amplitude was $10.3^{\circ} \mathrm{C}$. In this interval the number of patients with cardiovascular and respiratory disorders increased to 157.

Between 21.01 and 29.01, a drop in air temperature to an average of $-4.6^{\circ} \mathrm{C}$ was associated with an increase to 149 in the number of patients with cardiovascular, digestive and respiratory disorders.

On 21.01.2019 the greatest number of patients with digestive disorders (9) was recorded at the two doctor's offices, out of a total of 40 patients. During this day, temperature was negative, with high relative humidity, maximum cloudiness and very low solar radiation, atmospheric pressure was $6 \mathrm{hPa}$ above the normal value and wind speed was medium to low.

On 28.01.2019, the largest number of patients with respiratory disorders (16) was recorded out of a total of 32 patients. The average daily temperature was negative, with high humidity and nebulosity and low solar radiation, atmospheric pressure was $12 \mathrm{hPa}$ below the normal value and there were only light gusts of wind. Particulate matter pollution exceeded the daily limit values for the protection of human health over four days in the Burdujeni area. 
The five working days of week six of 2019 (04-08.02.2019) had the largest number of weekly consultations in the entire year - 247 patients (49.4 / day). Interestingly, this was also the week in which the largest number of young people went to consultations (40), of which 35 requested medical assistance on 04.02.2019 (Fig. 17). This interval was characterized by decreasing temperature, high humidity values, as well as rapidly increasing atmospheric pressure and particulate matter pollution above the daily levels in Burdujeni area.
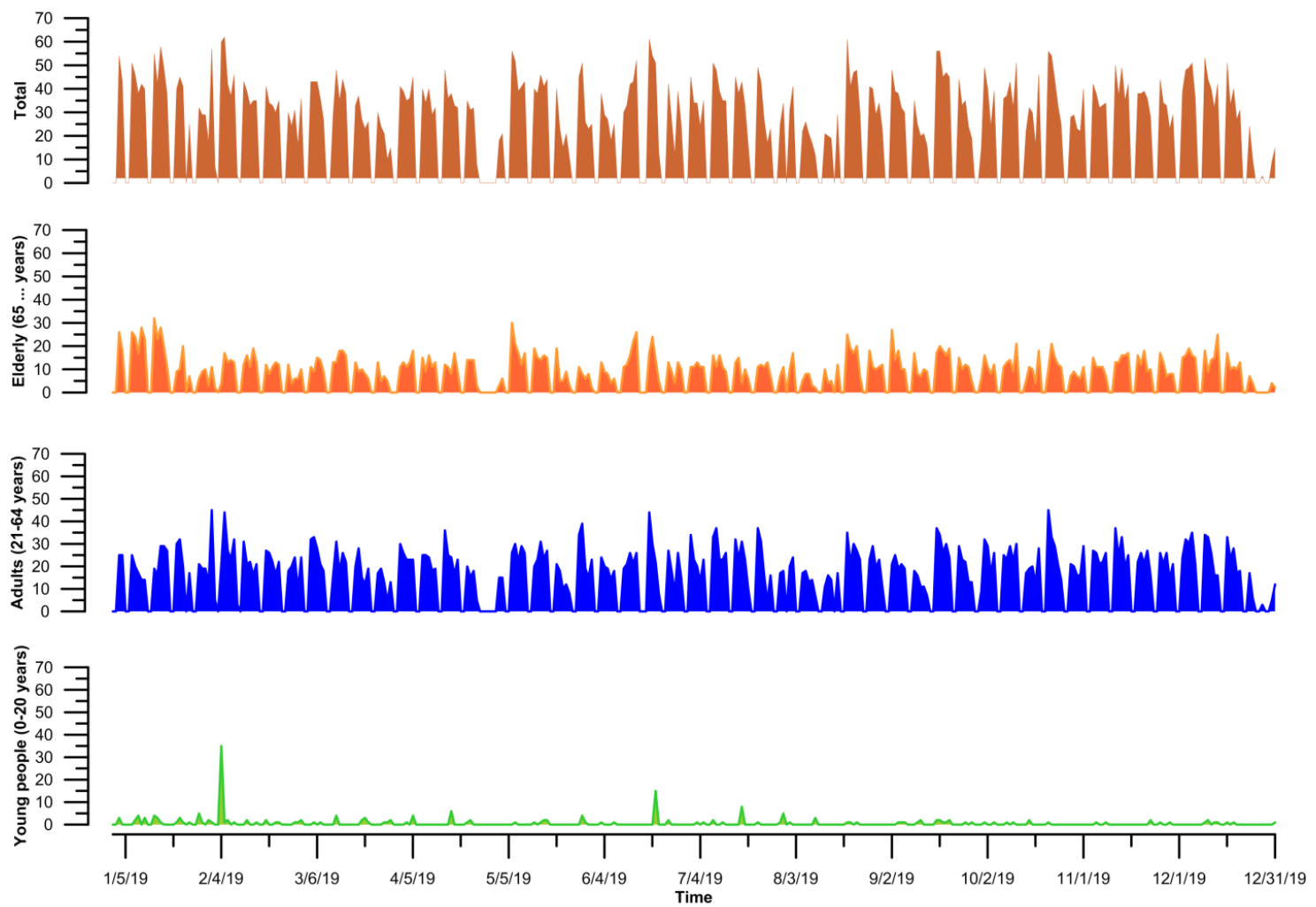

Figure 17. Interdiurnal variability of the number of patients belonging to different age groups, who received medical assistance in the two CMT_SV_2019

On 19.08.2019, 39 patients with cardiovascular diseases received medical assistance - a maximum for this type of disease in 2019 (Fig. 18). Maximum temperature for that day reached $31^{\circ} \mathrm{C}$, relative humidity was moderate, atmospheric pressure was above normal and rising, wind speed was low and the air slightly polluted with particulate matter.

On 16.09.2019 there was a maximum in the number of patients with locomotor disorders who received medical assistance (12 out of a total of 56). On that day, average temperature was normal, but the day-night temperature variability was over the $20^{\circ} \mathrm{C}$ threshold, with an extremely hot day and a cold night. Atmospheric pressure was close to normal, on a decreasing trend, relative humidity was reduced and clouds almost absent. 


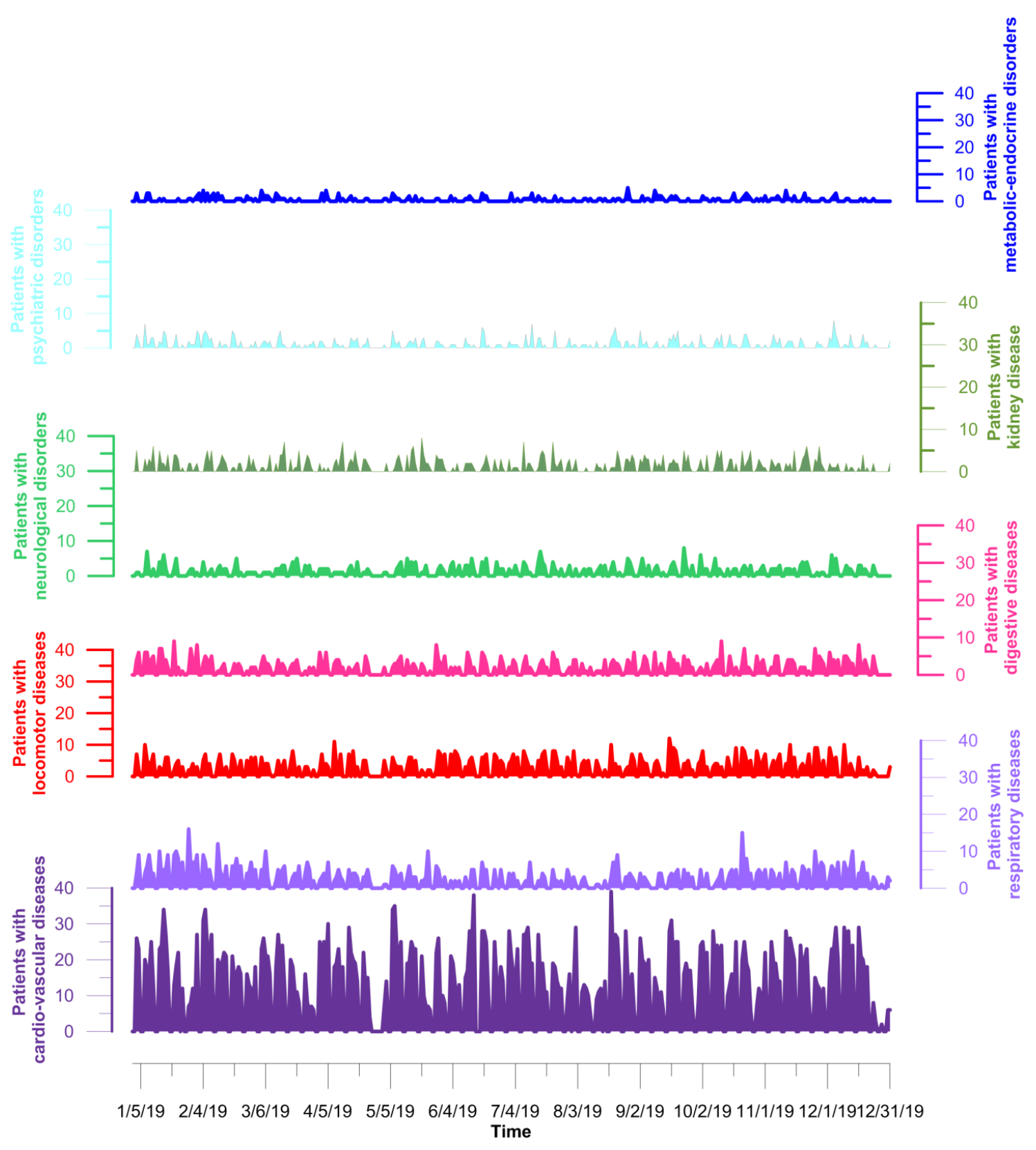

Figure 18. Interdiurnal variability of the number of patients with different conditions who received medical assistance in the two CMT_SV_2019

On 23.09.2019 out of 44 patients consulted, 8 were suffering from neurological conditions. The meteorological conditions for this day were characterized by normal atmospheric pressure, low wind speed and average cloudiness and air humidity. Air temperature followed an increasing trend, but with large diurnal thermal variations, i.e., around $20^{\circ} \mathrm{C}$.

On 11.10.2019 there was a relatively large number of patients with digestive disorders $(9$ patients). This increase was associated with relatively low temperature values (around 10 ${ }^{\circ} \mathrm{C}$ ), which followed a slightly decreasing trend and showed day-night variations of over $15^{\circ} \mathrm{C}$ in the previous days and $10^{\circ} \mathrm{C}$ in the day in question. The weather was dry, with low wind speed and atmospheric pressure increased compared to the previous day with 9 $\mathrm{hPa}$, reaching $1019.5 \mathrm{hPa}$. 
On 04.12.2019, a greater number of patients with mental disorders (8) were consulted. Meteorological conditions were characterized by an average temperature of $-2.3^{\circ} \mathrm{C}$, with temperature variability reaching $9.6^{\circ} \mathrm{C}$ and an increase in pressure by more than $10 \mathrm{hPa}$ compared to the previous day, reaching $1028.1 \mathrm{hPa}$, associated to an average wind speed of $0.3 \mathrm{~m} / \mathrm{s}$ (Fig. 19).

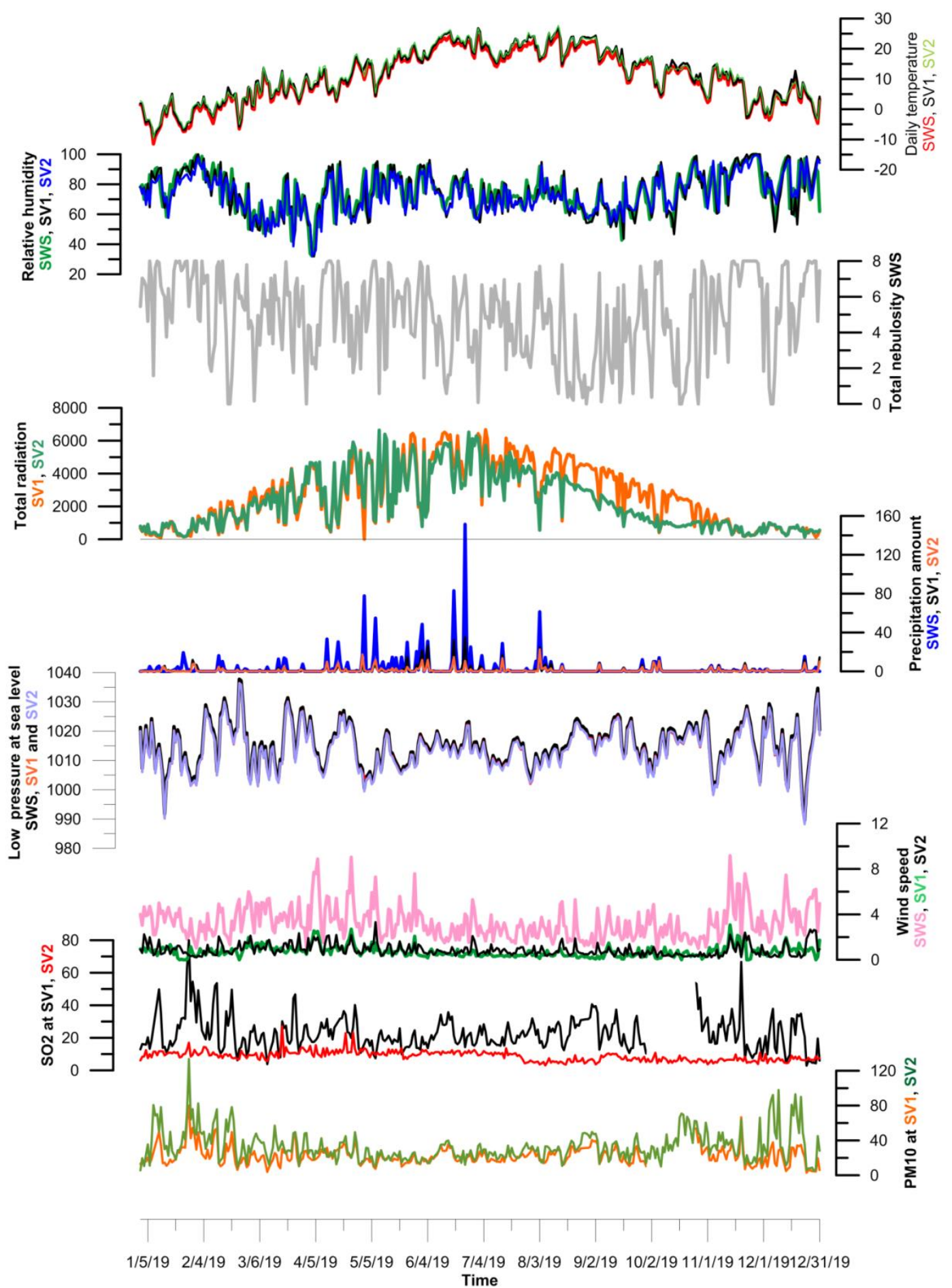

Figure 19 Interdiurnal variability of the main meteorological elements at the Suceava weather station SWS, Suceava 1 - SV1 and Suceava 2 - SV2 weather and air quality measurement stations and of the concentrations of two air pollutants (SO2 and PM10) at the SV1 and SV2 air quality measurement stations in 2019 
Based on the description of the dynamics in meteorological variables and medical conditions in 2019 in Suceava (Figs. 17, 18, 19), temperature was likely the main meteorological element which triggered the occurrence or exacerbation of different pathologies. It was likely followed by other elements of the biometeorological matrix such as humidity, wind/calm and atmospheric pressure. Neither cloudiness, sunshine duration or global radiation can be ignored. All the aforementioned elements are in close interdependence and may affect the human body one at a time or trough extremely different interactions. The diurnal and annual temperature variations are required during thermoregulation. The thermoregulatory function of the body has a seasonal variability due to the successive demand for defense against cold (winter) and hot (summer) conditions. When certain temperature thresholds are exceeded (positive in the warm season, negative in the cold season; deviations from this pattern are also possible, with cold waves and massive cooling in the summer / warm season or marked warming during the winter / cold season) seasonal or non-seasonal pathologies may occur anytime, likely linked to (high / low) temperature, which practically causes an annual morbidity regime with two (or more) maxima, that are more or less evident. The interaction with other elements may lower and even cancel the periodic pattern in morbidity, so that due to the multivalent impact of the meteorological elements on the different diseases, it is difficult to define an annual regime of the different diseases. Yet, most of the pathologies analyzed had predictable seasonal variation. Few diseases (e.g., respiratory) showed predictable intermonthly patterns, whereas metabolic-endocrinological disorders could not be fitted into a sufficiently well-defined temporal pattern.

\section{CONCLUSIONS}

It is easy to speculate on the impact of meteorological factors on the human body, however, such links are more difficult to demonstrate and quantify. Although the present study is based on a single year of meteorological and medical observations, it manages to highlight the annual regime of some medical conditions and discuss their meteorological causality. Following the analysis of the medical and meteorological data we found that the population of Suceava Municipality shows a greater risk to illness during the cold season and the autumn and winter months. The strongest causal relationships were found between the meteorological factors and the occurrence of respiratory diseases. Moreover, the cardiovascular, locomotor, digestive, neurological, renal and mental disorders showed a noticeable link with meteorological variability, with an annual evolution parallel to that of some meteorological variables. For endocrinological metabolic disorders, no temporal patterns or links with weather patterns were identified.

\section{REFERENCES}

[1] Enache L. Biometeorologie şi bioclimatologie. Climatul şi bioclimatul staţiunilor balneare şi România, Editura Sitech, Craiova, 582 p, 2016.

[2] Barnea E. Echilibrul termic al organismului uman (microclimatul și sănătatea), Editura Medicală, București, 1982.

[3] Croitoru A.E., Sorocovschi V., Introducere în bioclimatologia umană, Casa Cărții de Știință, Cluj-Napoca, 2012. 
[4] Piticar A., Cheval S. Frighenciu M. A review of recent studies on heat wave definitions, mechanisms, changes, and impact on mortality, F. G. Vol. XVIII, Issue 2, pp. 96-114, 2019.

[5] Becancenot J. P. Premières données sur les stres bioclimatiques moyens en France Annales de géogr., Nr 459, LXXXIII, 1974.

[6] Teodoreanu E, Gaceu O. Turism balneoclimatic în România, Editura Universității din Oradea, pp. 223, 2013.

[7a] Teodoreanu E., Mihăilă D. Is the bioclimate of Suceava Plateau confortable or uncomfortable? Analysis based on TEE and THI, PESD, Vol. 6 no. 1/2012, 2012.

[7b] Teodoreanu E., Mihăilă D. Is the bioclimate of Suceava Plateau confortable or uncomfortable? Analysis based on wind cooling power index and skin and lung stress index", PESD, Vol. 6 no. 1/2012, 2012.

[8] Licht S. Medical climatology, Elisabeth Licht Publ., New Haven, 1964.

[9]Mihăilă D. Atmosfera terestră. Elemente de favorabilitate sau nefavorabilitate pentru organismul uman și activităţile turistice, Editura Sedcom Libris, Iași, 233p, 2014.

[10] Teodoreanu E. Bioclimatologie umană, Ed. Academiei Române, Bucureşti 2002.

[11] Enache L. Biometeorologie, Editura Axa, București, 2001.

[12] Teodoreanu E. Geografie medicală, Editura Academiei Române, Bucureşti, 2004.

[13] Piery M. Traite de climatologie biologique et medicale, I-III, Ed. Masson, Paris, 1934.

[14] Missenad A. L’homme et le climat, Libr. Plen, Paris, 1937.

[15] Teodoreanu E. Date preliminarii asupra foehnului de la Buziaş, Trav. Station „Stejaru”, Pângăraţi, 1979.

[16] Mihăilă D., Tanasa I., Bistricean I. P. Extreme weather interval types in Suceava: frosty and tropical intervals, PESD, Vol. 7, no. 1, 2013. 